\title{
Inventário de Projetos Urbanos Digitais
}

\author{
Digital Urban Projects Inventory
}

- Elena de Pauli Namba

Universidade São Judas Tadeu, Brasil

e.pnamba@gmail.com

- Maria Carolina Maziviero

Universidade São Judas Tadeu, Brasil

mcarolmazi@hotmail.com

\begin{abstract}
This paper is the result of a survey of urban projects that use digital technologies to meet the needs and complexities of contemporary urban environments. The objective is to understand these new design methods applied to the urban scale and systematize information on the recent production. For this, we proposed an inventory that utilized the three types of design process defined by Rivka Oxman, to create categories and compose cataloging records on each project.
\end{abstract}

Keywords: Urban Projects, Digital Thought, Inventory, Generative Systems, Design Process

\section{Introdução}

Com o objetivo de difundir a tendência contemporânea de aplicação de novas tecnologias à atividade projetual e aprofundar o conhecimento sobre esse método de trabalho, este artigo visa inventariar a produção recente de projetos urbanos vinculados aos processos digitais. Contudo, para atingir o objetivo de criar um inventário precisou-se, em primeiro lugar, entender essa metodologia projetual contemporânea que difere dos métodos tradicionais.

Dentre os novos métodos de projeto em urbanismo existe uma corrente vinculada à tecnologia e processos digitais. Essa nova metodologia adota processos mais flexíveis e adaptáveis para ser capaz de responder às demandas em constante evolução da cidade contemporânea. Tal corrente fundamenta-se, principalmente, em sistemas de desenho paramétrico, já amplamente utilizado nas indústrias aeroespacial e automotiva. Neste tipo de desenho, o foco de interesse não é a forma em si, mas os parâmetros que a geram. Parâmetros de configuração do espaço podem ser cruzados com uma infinidade de outros referenciais fundamentais para a compreensão da dinâmica urbana, tais como ambientais, funcionais, ou padrões de sustentabilidade.

Por se tratar de uma metodologia projetual ainda pouco difundida nas universidades brasileiras, a criação desse inventário de projetos urbanos digitais funciona tanto como forma de difusão de conhecimento quanto como um ponto de partida para analises sobre a emergência dessa metodologia de desenho urbano, buscando compreender as perspectivas de aprimoramento da atuação do arquiteto urbanista na qualificação do ambiente construído.

\section{Pensamento digital}

Pensar por meio do computador significa utilizar ferramentas digitais disponíveis em todo o processo de projeto com o objetivo de otimizar a ação e buscar relações entre os parâmetros adicionados, desde a ideia inicial até o produto final. Com relação a prática projetual, o pensamento digital rompe com o método tradicional, no qual existe uma ideia inicial que é então representada através da utilização do desenho manual (croqui) e, em seguida, tem-se a tentativa de discussão. Somente por último, com o projeto finalizado, usase ferramentas digitais com o intuito de representar o produto acabado. O modelo tridimensional, a maquete, poucas vezes é utilizado como parte do processo de projeto.

O modelo tridimensional, no caso do pensamento digital, é parte ativa no processo projetual, pois através dele podem ser feitas discussões e reelaborações, uma vez que o modelo possibilita uma melhor visualização espacial do projeto. Nesse método, entende-se que o arquiteto precisa estar constantemente pensando o projeto e, por isso, todos os meios possíveis para otimizar o tempo gasto com representação é revertido em tempo de pensamento projetual, utilizando ferramentas digitais.

Sendo assim, o pensamento digital condiz com um processo de projeto não linear, isto é, não existe uma sequência que precisa ser seguida para chegar a um resultado. O exemplo a seguir ilustra a diferença entre os dois tipos de 
processo de projeto. Cabe enfatizar, entretanto, que mesmo sendo processos diferentes, o objetivo deste trabalho não é tecer argumentação sobre a substituição de uma metodologia por outra. Procurou-se aqui ampliar a discussão sobre as possibilidades abertas pela introdução da tecnologia ao desenho urbano.
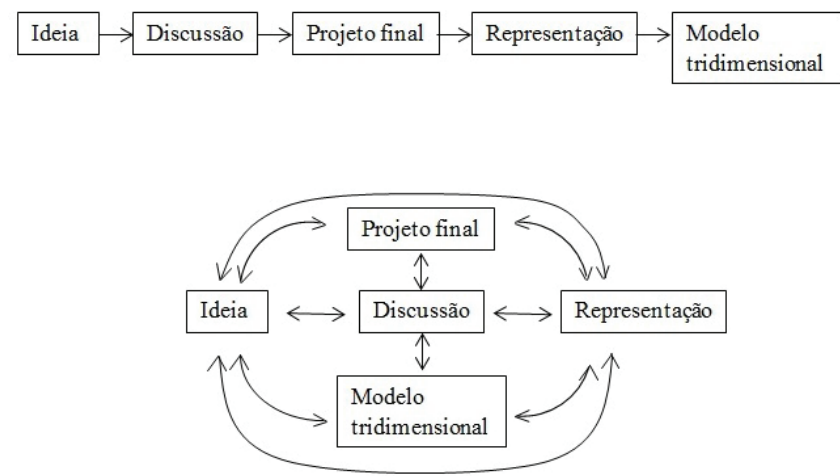

Figura 1: modelo linear e modelo não linear de processo de projeto. Fonte: Oxman, 2014. Tradução e elaboração própria.

O que é e para que serve um inventário?

O inventário é uma descrição detalhada de dados levantados, que podem ser bastante distintos entre si e podem estar em diferentes suportes: textos, imagens, vídeos, etc. A diagramação do inventário muda de acordo com os dados catalogados e a informação que deseja ser transmitida. Este sistema também pode ser utilizado apenas para guardar dados como um registro.

O inventário é mais comumente utilizado na área judicial, na forma de um documento que registra bens de modo geral, seja de pessoa falecida para que se possa proceder com a partilha dos bens, casal em processo de separação ou ainda como registro dos bens de uma empresa. Contudo, para além disso, o sistema de inventariar dados, por conter uma descrição detalhada ou minuciosa de algo, também é bastante utilizado para descrição, análise e difusão de conhecimento. Assim, os locais onde os inventários são mais encontrados, além do campo judicial, são nas bibliotecas. Como o inventário é um documento de registro é muito comum ser utilizado nas bibliotecas como forma de catalogação de livros, especialmente, aqueles mais antigos. Organizando-os por meio de um inventário, a biblioteca consegue documentar todos os seus bens para futura consulta ou apenas para registro, com o critério de raridade do material.

Além das aplicações supracitadas, essa forma de sistematização de dados é bastante utilizada pelos departamentos que cuidam da proteção de bens com interesse histórico e cultural, sejam eles materiais ou imateriais. É justamente esta última aplicação que mais se aproxima do escopo desta pesquisa, especialmente, por possuir relação com o campo da Arquitetura e Urbanismo.

\section{Porquê e como inventariar projetos urbanos digitais}

A metodologia decorrente da junção entre desenho urbano e ferramentas computacionais vem sendo crescentemente utilizada em escritórios internacionais. Também é crescente o númerodeuniversidadesestrangeirasquevem desenvolvendo pesquisas avançadas sobre interação entre a computação e a atividade projetual em arquitetura e, em menor grau, em urbanismo. No Brasil, contudo, nota-se pouco interesse nessa metodologia aplicada ao projeto na escala urbana, quer em sua porção formal, quer em projetos de urbanização de áreas extremamente complexas, tal qual favelas. Por ouro lado, também percebe-se pouca divulgação de projetos de pesquisa com caráter experimental que envolvam a escala urbana e processos digitais nas universidades brasileiras. Assim, buscou-se desenvolver um inventário, não só como instrumento de registro e sistematização de dados, mas também como forma de difusão do conhecimento.

Com o inventário de projetos urbanos digitais conseguese registrar uma quantidade considerável de projetos urbanos desenvolvidos a partir de processos digitais. Além disso, mostra que apesar de ser uma produção recente e ainda muito experimental, vem crescentemente sendo estudada e utilizada. Assim, a pesquisa traz consigo a discussão sobre novos métodos de pensar as intervenções que ultrapassam a escala do edifício.

Deste modo, buscou-se uma série de referências sobre diferentes modos de inventariar dados, procurando por modelos de sistematização e análise de informações recolhidas. Nestas referências, identificou-se pontos importantes para a elaboração das fichas que compõem o inventário.

No campo da arquitetura e do urbanismo, uma referência importante foi o método empregado pelo Departamento de Patrimônios Históricos de São Paulo (DPH). O departamento possui um reconhecido inventário de registro dos Bens Tombados em São Paulo, que tem como principal finalidade a catalogação e a descrição dos imóveis da cidade. O inventário apresenta dados importantes para o registro das obras catalogadas, tais como uso, data de construção, materiais da construção, localização, estado de conservação, etc. Além de todos esses dados é importante conter foto e, se possível, uma atual e outras de diferentes épocas. Por fim, apresenta um memorial, que também é imprescindível para este tipo de inventário, já que a história de formação da construção e suas modificações ao decorrer do tempo podem ajudar nos procedimentos de intervenção e restauro da obra.

Além do inventário de patrimônio histórico existe também o inventário de registros acadêmicos do LAPAC Unicamp (Laboratório de Automação e Prototipagem para Arquitetura e Construção da Unicamp). Este é outro exemplo de organização e sistematização de dados, cuja finalidade foi o registro das atividades realizadas no laboratório por alunos que possuem pesquisas voltados ao uso das tecnologias digitais na arquitetura. Nesse inventário, além de descrever as atividades desenvolvidas no laboratório, bem como os 
métodos de trabalho, também estão registrados os resultados das pesquisas e os pesquisadores envolvidos. Nesse caso, o uso de fotos é importante para apresentar o processo de trabalho e o resultado final.

A partir destes dois tipos de sistematização de dados, com finalidades diferentes, buscou-se compreender os critérios específicos e de maior relevância para cada caso. Em ambos os casos estudados nota-se a importância das informações de identificação do dado catalogado, ou seja, nome, data, local, autor, etc., bem como a hierarquia de apresentação desses elementos.

Assim, para inventariar projetos urbanos digitais, muitas vezes não construídos, pode-se apontar alguns critérios imprescindíveis para a ficha cadastral: i) apresentar informações de identificação do projeto, como autor/ escritório, local, data de projeto e/ou de execução; ii) descrever detalhadamente o projeto e os elementos que o compõe; iii) estabelecer critérios ou categorias para uma explicaçãosíntese sobre o método projetual adotado; iv) apresentar imagens do projeto e/ou da obra.

\section{Sistematização de dados}

Para a elaboração das categorias foi feito um estudo dos trabalhos dos autores basilares que percorreram o tema dos processos de projeto desenvolvidos a partir de ferramentas computacionais. Importante enfatizar que os métodos projetuais explicados, na maioria dos textos estudados, não são específicos de projetos urbanos. Eles dizem respeito a utilização das ferramentas digitais no processo de projeto, em geral, na escala arquitetônica ou do objeto. Sendo assim, além de compreender esse método de modo geral, buscouse estabelecer paralelos sobre sua possível aplicação na escala urbana.

A partir da revisão bibliográfica, foram encontradas conceituações que pareciam suficientes para a criação das categorias do inventário deste trabalho. Entretanto, ao analisar os projetos levantados, os conceitos não eram identificados com clareza nos projetos ou não possibilitavam a compreensão adequada dos processos projetuais a partir do material disponibilizado.

Por fim, elegeu-se o texto de Oxman (2008), "Digital architecture as a challenge for design pedagogy: theory, knowledge, models and medium" como norteador das categorias de análise e sistematização de dados nesta pesquisa. Neste artigo de 2008, Oxman analisa e explica a diferença de três tipos de processo de projeto: formativo, generativo ou performativo. A escolha pela utilização dos conceitos de Oxman para delinear as categorias que nos ajudaram a sistematizar os projetos levantados surgiu por conta do tratamento de caráter generalista utilizado pela autora. Em outras palavras, os três processos projetuais são apresentados como sínteses dos métodos mais encontrados na produção recente do design apoiado em processos digitais. Portanto, acredita-se que as definições de Oxman seriam ideais para sistematizar os dados levantados a fim de obter melhor resultado na identificação.

Cabe aqui destacar duas questões fundamentais: i) a autora trata de diversas escalas, e não especificamente sobre a urbana; ii) a aplicação dos conceitos basilares de Oxman (2008) para organização de um amplo universo de amostragem da produção recente de projetos urbanos tem caráter unicamente experimental e, portanto, as aproximações e paralelos traçados por nós podem não corresponder a realidade. Trata-se de um exercício teórico prático desenvolvido durante a graduação, em pesquisa de iniciação científica.

\section{Modelos Formativos}

Segundo Oxman (2008), "formativo" não se refere a forma, a estética do modelo, mas sim a formação desse modelo. No caso dos modelos formativos, o desenvolvimento do processo de formação do projeto é levado em consideração como foco principal, "duas técnicas digitais estão associadas com este modelo: animação e desenho paramétrico" (OXMAN, R. 2008, p. 8).

Mas, segundo Oxman, tanto na animação quanto no desenho paramétrico, a formação do modelo desempenha o papel principal. Em animação o modelo possui ligação com o desenho dinâmico, ou seja, a formação do modelo está voltada ao desempenho dinâmico que se busca em seu resultado. No caso do desenho paramétrico, a principal busca são as variações que se consegue no modelo através dos parâmetros inseridos, bem como por sua manipulação. Quando se insere parâmetros na formação do modelo, a forma não tem importância de inicio, o que se busca é a associação dos parâmetros à geometria.

Para associar os projetos catalogados com este tipo de modelo buscou-se a compreensão deste processo de formação em relação ao resultado. Isto é, foram separados todos os projetos que possuem relação entre forma final e processo de projeto. Todos os projetos que possuem relação direta (visualmente) do processo de projeto com o resultado foram colocados nesta categoria.

\section{Modelos Generativos}

Os modelos generativos estão associados ao processo de geração do modelo de acordo com seus parâmetros de contexto. Nesse caso não existe nenhuma ligação com o resultado final do projeto, ou seja, a forma não faz parte do processo de projeto, ela é um resultado.

Segundo a autora, os dois processos mais conhecidos dentro dos modelos generativos são os modelos evolutivos e gramática da forma. Nos modelos evolutivos temos o conceito do crescimento natural, mutação e reprodução. Todos esses conceitos provem da computação evolutiva e possuem a seleção natural como principal fundamento. Neste caso, os parâmetros inseridos são analisados conforme seu desempenho, de acordo com sua família e sua geração. Ao final da análise, são separados somente os indivíduos que possuem maior desempenho e então estes indivíduos são reanalisados, gerando um ciclo continuo até que se obtenha um resultado satisfatório. 
Já a gramática da forma é um método de projeto que consiste em uma sequência lógica, na qual há uma substituição de caracteres a fim de gerar novas sequências. Esse processo gera possibilidades de elaborações de formas complexas e também a evolução otimizada dessas novas gerações, de acordo com as substituições desses caracteres. A utilização desse método suscita uma leitura própria do objeto produzido e facilita sua compreensão.

A catalogação de projetos a partir dessa definição foi possível graças ao material disponibilizado pelos escritórios. Neles, estava claro que a forma final não era o objetivo, mas sim o contexto de evolução dos modelos durante o processo de projeto.

\section{Modelos Performativos}

Neste modelo o desempenho é o principal foco do processo de projeto. A forma também não possui importância no processo, mas sim os desempenhos de performance do modelo. Desta maneira, são definidos critérios de estudo para a simulação de desempenho, como por exemplo, análise ambiental, que funcionam como parâmetros. São eles, então, quem definem as alterações que o modelo sofrerá em sua forma final, isto é, a forma é o resultado.

O modelo performativo possui caráter de simulação, ou seja, o projeto pode sofrer diversas alterações se houver performances variadas, como por exemplo, analise de conforto ambiental, captação solar, sombreamento, força do vento, etc. Além de analises de conforto ambiental também existe a analise de desempenho de fluxos, onde podem ser analisados os fluxos de pedestre, automóvel, fluxo hídrico, entre outros.

No caso desse processo de projeto, buscou-se analisar dentro dos projetos catalogados aqueles que possuem como principal característica a busca pelo desempenho e nos quais pode-se identificar claramente essas relações de analises no produto final.

\section{Resultados}

Como resultado do inventário de projetos urbanos digitais proposto, conseguiu-se chegar ao modelo de ficha apresentado a seguir. Acredita-se que este modelo atende as necessidades de informação sobre os projetos levantados. Além disso, a ficha concretiza o esforço em aplicar as definições basilares de Oxman (2008) à produção contemporânea de projetos na escala urbana apoiados em ferramentas computacionais.

Este inventário registrou no total trinta projetos e, como mencionado anteriormente, encontrou-se alguma dificuldade para sistematizar os dados levantados. Assim, estabeleceu-se a classificação encontrada no trabalho de Oxman, mas caberia ainda um novo exercício para aprimoramento das categorias.

Importante destacar que a classificação nas categorias deu-se pelo produto final disponibilizado pelos autores dos projetos, ou seja, foram feitas análises, caso a caso, a partir das informações coletadas. Entretanto, apesar de conseguir chegar em um resultado favorável de classificação, acreditase que se fosse possível estudar especificamente o processo de cada projeto levantado, conseguir-se-ia um inventário mais detalhado, que serviria para estudos de variados temas sobre essa metodologia.

O resultado dessa sistematização de dados foi apresentado em setembro de 2015, como conclusão do trabalho de iniciação científica junto a Universidade São Judas Tadeu. Apresenta-se, aqui, apenas o modelo de ficha desenvolvido e a metodologia utilizada.

Índice explicativo da ficha de catalogação:

1: Nome do projeto.

2: Local e Data do projeto

3: Especificação do projeto

4: Responsáveis pelo projeto, podendo ser escritório, arquitetos e urbanistas ou mesmo estudantes (caso de concurso).

5: Categoria do projeto.

6: Memorial descritivo do projeto e justificativa da classificação. 7: Imagens, fotos ou figuras.

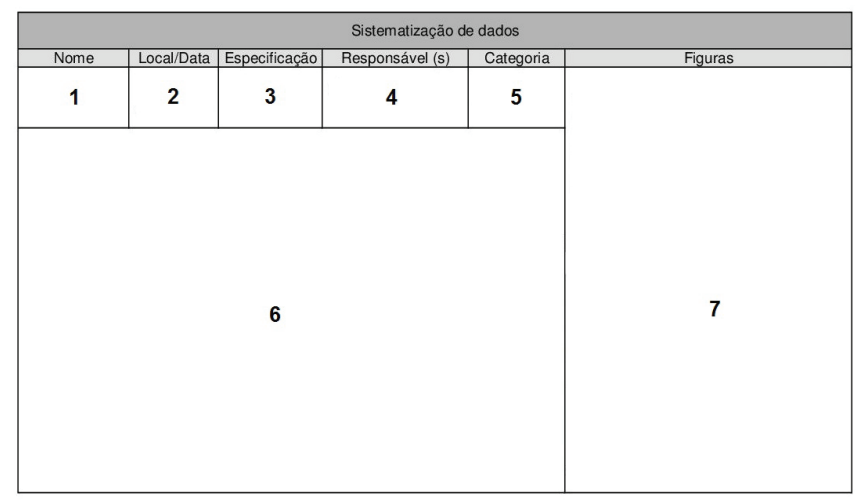

Figura 2: Modelo de ficha. Fonte: elaboração própria, 2015.

\section{Considerações finais}

O urbanismo na era digital é um assunto ainda pouco discutido no Brasil, embora já venha se consolidando como uma nova linha de pesquisa no campo dos estudos urbanos internacionalmente. Ao analisar as discussões sobre este assunto pode-se perceber que as intervenções recentes no espaço urbano possuem caráter mais complexo por conta das múltiplas variáveis contidas na cidade. Uma metodologia de intervenção que vincule projeto e processos digitais pode ampliar a possibilidade de cruzamento de dados e de novas simulações, melhorando o desempenho e a capacidade de aderência desses projetos a realidade complexa da cidade.

Neste sentido, apesar de possuir caráter experimental, a produção de um inventário de projetos urbanos digitais pretendeu não só organizar um amplo universo de amostragem do assunto, como também compreender esses processos, além de trazer questões atuais para o campo de pesquisa do Urbanismo. 
Segundo diversos autores, vivemos a era da III Revolução Industrial, ainda não conclusa, trazida pela rede mundial de computadores - a Internet. Contudo, apesar do grande número de informações e dados em circulação, há a necessidade de organizar e sistematizar o conhecimento. Apesar do grande númerodesitesespecializadosemarquitetura contemporânea, a quantidade dos que se dedicam especificamente aos projetos na escala urbana é inexpressiva.

Entende-se que a continuação da presente pesquisa pode ainda avançar na criação de uma plataforma aberta e colaborativa, a fim de ampliar a difusão e a troca de conhecimento sobre metodologias de projeto alternativas ou complementares às tradicionais.

\section{Referências}

GUIA DE BENS CULTURAIS DA CIDADE DE SÃO PAULO/ Departamento do Patrimônio Histórico. São Paulo: Imprensa Oficial, 2012.
KOLAREVIC, Branko. Architecture in the Digital Age: Design and Manufacturing. London: Spon Press, 2003.

MITCHELL, W. J. The theoretical foundation of computeraided architectural design. Environment and Planning B: Planing and Design, Londres, n. 2, 1975, p. 127-150.

OXMAN, Rivka. Digital architecture as a challenge for design pedagogy: theory, knowledge, models and medium. 2008. Disponível em: http://tx.technion.ac.il/ rivkao/topics/ publications/Oxman_2008_Design-Studies.pdf. Acessado em: 04/08/2014.

OXMAN, Rivka. Theory and design in the first digital age. 2005. Disponível em: http://tx.technion.ac.il/ rivkao/topics/ publications/Oxman_2006_Design-Studies.pdf. Acessado em: 04/08/2014.

OXMAN, Rivka. Think-maps: teaching design thinking in design education. 2004. Disponível em: http://tx.technion. ac.il/ rivkao/topics/publications/Oxman_THink\%20 Map\%202004_Design-Studies.pdf. Acessado em: 04/08/2014. 